\title{
RELAÇÕES DE GÊNERO E ASCENSÃO FEMININA NO AMBIENTE ORGANIZACIONAL: UM ENSAIO TEÓRICO
}

\author{
Gender relations and feminine ascension at the \\ Organizational environment: a theoretical essay
}

\section{André Ribeiro de Oliveira ${ }^{1}$ \\ Luiz Eduardo Gaio ${ }^{2}$ \\ Carlos Alberto Grespan Bonacim ${ }^{3}$}

\section{Resumo}

As mudanças ocorridas nas últimas décadas estabeleceram uma nova forma de relacionamento entre os seres humanos. As mulheres estão, cada vez mais, deixando de pertencer à esfera privada do lar para ocuparem um lugar na sociedade que já não comporta mais apenas figuras masculinas. Por meio deste trabalho, procurou-se delinear a trajetória de luta das mulheres nesse sentido, desde o início da empreitada feminista até os dias atuais, além de ilustrar o panorama organizacional brasileiro no que tange à participação feminina no mercado de trabalho, por meio de uma caracterização dos avanços referentes às questões de relações de gênero. Para tanto, realizou-se uma pesquisa bibliográfica sobre gênero, movimento feminista e participação das mulheres no mercado de trabalho. A confecção deste estudo permitiu concluir

\footnotetext{
${ }^{1}$ Mestrando em Administração pela Universidade Federal de Lavras (UFLA). End.: Rua das Palmeiras, 471, Eldorado, CEP: 37.200-000, Lavras, MG. Fone: (16) 3602-3917. E-mail: andre180282@yahoo.com.br

${ }^{2}$ Mestrando em Administração de Organizações pela Universidade de São Paulo, Faculdade de Economia, Administração e Contabilidade de Ribeirão Preto (FEA-RP/USP). End.: Rua das Palmeiras, 471, Eldorado, CEP: 37.200-000 Lavras, MG. Fone: (16) 3602-3917. E-mail: lugaio@yahoo.com.br

${ }^{3}$ Doutorando em Ciências Contábeis, Universidade de São Paulo - Faculdade de Economia, Administração e Contabilidade (FEA/USP). End.: Rua Romeu Engrácia de Faria, 210, ap. 15A - Jd Nova Aliança - CEP: 14.026-585, Ribeirão Preto/SP. Fone: (16) 3602-3917. E-mail: carlosbonacim@yahoo.com.br
} 
que, apesar de ainda existirem alguns entraves, há uma tendência de maior valorização das mulheres, além disso, a sociedade e as organizações estão se dispondo a enfrentar as conseqüências desse novo contexto e ampliar o enfoque diretivo e a tomada de decisão para a inserção dos valores femininos, respeitando a percepção das mulheres tanto nas questões sociais como nas organizacionais. Bibliográfica.

Palavras-chave: Relações de Gênero; Mulher; Feminismo; Organizações, Pesquisa

\begin{abstract}
The changes that occurred in the last decades have established a new kind of relationship between people. Women are leaving the private spot of home to occupy a place in society that does not stand only male figures anymore. This paper seeks to show the women's trajectory, since the beginning of the feminist undertaking until nowadays, besides that, it shows the advances concerning issues related to gender. Therefore, it was realized a bibliographic research about gender, feminist movement, and women's participation in the labor market. From the accomplishment of this study, it can be concluded that, although some obstacles still remain, there is a tendency of increasing the value of women; moreover, society and organizations are willing to face the consequences of this new context and enlarge the directive focus and the decision-making to insert feminine values, respecting women's perception regarding social and organizational subjects.
\end{abstract}

Keywords: Gender Relations, Woman, Feminism, Organizations, Bibliographic Research.

\title{
1 Introdução
}

Diferentes sociedades, em estágios díspares, possuem diversos valores, aos quais homens e mulheres estão relacionados de forma distinta. Sabe-se que o patriarcado é um sistema que perdura, pelo menos, há três mil anos, um período tão extenso que não é possível dizer se é um processo cíclico ou não, pois as informações que se dispõem acerca das eras pré-patriarcais são mínimas. O que é certo, nesses últimos três mil anos, é que a civilização ocidental e suas precursoras, assim como a grande maioria das outras culturas, basearam-se em sistemas filosóficos, sociais e políticos em que homens - pela força, pressão direta ou através do ritual, da tradição, lei e linguagem, costumes, etiqueta, educação e divisão do trabalho determinam que papel as mulheres devem ou não desempenhar, e no qual a fêmea está, em toda parte, submetida ao macho (CAPRA, 1988).

Nas sociedades ocidentais do século XIX, o homem era responsável pela atividade econômica exercida fora do lar burguês; à mulher cabia o espaço doméstico e a responsabilidade da união da família. Segundo Leonard (2002), ideologias de nacionalismo, racionalidade e individualismo permitiram somente aos homens a habilidade de serem ativos na esfera pública, enquanto as mulheres eram separadas na esfera "distinta e fechada" da vida familiar privada.

Tomando como referencial de análise a sociedade, Bourdieu (1999, p. 18) estende a explicação da dominação masculina a todas as formações sociais, ao destacar que:

A ordem social funciona como uma imensa máquina simbólica que tende a ratificar a dominação masculina sobre a qual se alicerça: é a divisão social do trabalho, distribuição bastante estrita das atividades atribuídas a cada um dos dois sexos, de seu local, seu momento, 
seus instrumentos; é a estrutura do espaço, opondo o lugar de assembléia ou de mercado, reservados aos homens, e a casa, reservada às mulheres; ou, no interior desta, entre a parte masculina, como o salão, e a parte feminina, como o estábulo, a água e os vegetais; é a estrutura do tempo, a jornada, o ano agrário, ou o ciclo de vida, com momentos de ruptura, masculinos, e longos períodos de gestação, femininos.

Bourdieu (1999) enfatiza que a dominação masculina centrada na dominação simbólica é o princípio que justifica e legitima as demais formas de dominação/submissão exercitadas de maneiras singulares e múltiplas e, sendo diferentes em suas formas segundo a posição social, geográfica, espacial, étnica, de gênero e dos agentes envolvidos, se homogeneíza, separando e unindo, em cada universo social, homens e mulheres, mantendo entre eles uma mística linha de demarcação.

As mudanças ocorridas nas últimas décadas (globalização, mudanças tecnológicas, diversidade cultural da mão-de-obra, mercados consumidores cada vez mais exigentes, competição acirrada, dentre outras) modificaram a vida das pessoas e organizações e estabeleceram uma nova forma de relacionamento entre os seres humanos. É nesse cenário que surgem estudos, cada vez mais freqüentes, que tratam da questão de gênero no ambiente organizacional. Situações, até o momento entendidas como tradicionais na cultura social, como, por exemplo, o papel da mulher visto como de subordinação e o trabalho feminino como uma continuidade das tarefas domésticas, estão se alterando, o que gera modificações no mercado de trabalho.

As diferenças entre as mulheres e homens são óbvias, já que ocorrem concretamente em nível do corpo. O intrigante é que a sociedade tenha a necessidade de reinterpretá-las, transformando-as em desigualdades sociais que atingem diferencialmente mulheres do mundo inteiro. A crença na agressividade do macho e na passividade da fêmea é tão forte em nossa sociedade que as pessoas parecem não perceber que ocorrem rebeliões em presídios femininos; que a participação de mulheres em guerras e guerrilhas é uma constante através da história, até em países de tradição muçulmana, onde elas estão envolvidas em véus; e de que fêmeas de animais ferozes podem atacar e matar tanto quanto os machos. Whitaker (1988, p. 09) coloca bem essa questão:

A mulher é considerada passiva (não-agressiva), intuitiva (?), dócil e, portanto, submissa. No mundo do trabalho, tais mitos são manipulados para afastar as mulheres de certas profissões, mas não impedem que elas realizem pesadíssimas tarefas, desde que desvalorizadas socialmente. Ora, tais diferenças, ditas de temperamento, entre homens e mulheres são falsas. As verdadeiras diferenças ocorrem no nível do corpo e nada têm a ver com as abstrações culturais desvalorizadas dos 'diferentes'.

No final do século XX, esse intrigante fenômeno tornou-se finalmente um problema científico. Surgiram estudos, investigações, inquéritos e pesquisas sobre a mulher em todas as áreas do saber, graças a estímulos provocados, em boa parte, pela proclamação da década da mulher, a partir de 1975. Infelizmente os resultados dessas pesquisas permanecem restritos ao mundo acadêmico e a uma ou outra reportagem publicada em caderno de variedades da grande imprensa.

Por outro lado, em algumas regiões do globo - Europa Ocidental, Estados Unidos, Rússia -, as mulheres já avançaram bastante. Não por acaso, é nesses países que elas se apresentam mais ansiosas por novas conquistas. Compare-se a Grã-Bretanha - onde dirigem ônibus de 
dois andares, trabalham como jardineiras (profissão bem remunerada naquelas terras) e até são líderes de sindicatos poderosos - com os países árabes, onde, de maneira também desigual (diferentes países e/ou camadas sociais), as mulheres permanecem com seus rostos velados, impossibilitadas de interagir na plenitude da expressão facial (WHITAKER, 1988).

O "mundo das mulheres" é baseado em relacionamentos locais e íntimos - um legado da sociedade pré-industrial - enquanto o "mundo dos homens", pelo contrário, segue o modelo do capitalismo econômico, baseado na troca. No entanto, é nas conexões íntimas das mulheres com os valores da sociedade rural e pré-industrial e do seu conhecimento sobre a importância dos relacionamentos entre o indivíduo, a comunidade e a ecologia que dá um senso de "esperança renovada" aos estilos de administração nas organizações (LEONARD, 2002).

A divisão sexual no trabalho - incluindo a tendência de os homens monopolizarem os postos mais altos e privilegiados, enquanto as mulheres, frequentemente, ocupam, em sua maioria, níveis organizacionais mais baixos - tem se tornado aparente com o crescimento do debate sobre o tema gênero, que é visto como uma importante parte da vida organizacional.

Argumenta-se que masculinidades e feminilidades não formam simples padrões de dominação e subordinação, mas se interagem de formas mais complexas. Algumas características são convencionalmente entendidas - também por feministas - como princípios e valores femininos, como, por exemplo, trabalho intuitivo, emoção, relacionamentos íntimos de amizade no local de trabalho, ausência de hierarquia extensa, espaço limitado para o carreirismo etc. (FERGUSON, 1984).

Nas últimas décadas, o movimento pela "libertação das mulheres" conseguiu obter consideráveis ganhos sociais, políticos e econômicos, melhorando a situação de muitas mulheres. Simultaneamente os movimentos feministas contribuíram, em grande parte, para a análise cultural contemporânea. Diversas "teorias" feministas propuseram repensar as bases do conhecimento. Mas, apesar disso, a segregação sexual no âmbito organizacional ainda persiste como um fenômeno mundial, bem como a desigualdade salarial entre os sexos.

Whitaker (1988) afirma que a universidade reproduz a idéia de que existe uma divisão sexual do trabalho, uma vez que existem carreiras consideradas masculinas e carreiras consideradas femininas. Engenharia, principalmente mecânica, é carreira masculina, assim como a geologia e agronomia. Enfermagem e Serviço Social são exemplo de carreiras essencialmente femininas. Carreiras que implicam constante prestação de serviços são seguidas quase exclusivamente por mulheres. É o caso de enfermagem e serviço social.

Para Whitaker (1988), esse artificialismo que divide as carreiras em masculinas e femininas, muitas vezes, impede rapazes e moças de realizarem suas verdadeiras tendências profissionaisemfunção dos preconceitosqueorientam suasescolhas. Quandonúmeroequivalente de homens e mulheres cursarem enfermagem ou engenharia, haverá maior probabilidade de que as pessoas estejam realmente se preparando para a realização profissional.

Tarefas supostamente femininas (desvalorizadas no nível do lar), como num passe de mágica se transformam em rituais solenes quando a performance é realizada por homens. Cozinheiros, cabeleireiros, costureiros, são todos profissionais masculinos valorizadíssimos. Quando mulheres se profissionalizam nessa direção, elas não alcançam os mesmos níveis salariais e de status. Strober (1984) alerta para o fato de as profissionais do sexo feminino enfrentam o fenômeno da "gorjeta", em que profissões de nível superior, tipicamente masculinas e tradicionalmente bem remuneradas, sofrem quedas de poder aquisitivo quando passam a ser dominadas por mulheres.

No Brasil, as mulheres ocupam atualmente uma parcela bastante representativa do mercado de trabalho e, teoricamente, o mundo organizacional caminha a passos largos em 
direção à igualdade entre os sexos. No entanto, as diferenças, os preconceitos e os entraves ao desenvolvimento da vida profissional da mulher ainda não foram banidos das empresas.

De acordo com o Instituto Brasileiro de Geografia e Estatística (IBGE), citado por Uchinaka (2004), as mulheres representam quase metade da População Economicamente Ativa (PEA) do país e, desse total, 38\% encontram-se empregadas.

Dados do Censo Demográfico, realizado em 2000, mostram que havia 86.223.155 mulheres no Brasil, dentre as quais 11.160 .635 eram responsáveis pelos domicílios, o que corresponde a 12,9\%. Assim como nos censos anteriores, o de 2000 revelou uma presença maior de mulheres no total da população, sendo que, para cada 100 mulheres, havia no Brasil 96,93 homens; em termos absolutos, havia mais 2.647.140 mulheres do que homens. Segundo o IBGE (2002), a principal razão para esse fato seria o diferencial de mortalidade que determina uma vida média mais elevada para as mulheres. E a proporção de homens vem se reduzindo de forma contínua e discreta, passando de 98,7 em 1980, para 97,5 em 1991 e 96,9 em 2000.

\section{Objetivos}

As mulheres estão cada vez mais deixando de pertencer à esfera privada do lar para ocuparem um lugar na sociedade, que já não comporta mais apenas figuras masculinas. Por meio deste trabalho, procurou-se delinear a trajetória de luta das mulheres nesse sentido, desde o início da empreitada feminista até os dias atuais. Para tanto, realizou-se uma análise documental sobre gênero, movimento feminista e participação das mulheres no mercado de trabalho. Por meio de dados numéricos e considerações, procurou-se ilustrar o panorama organizacional brasileiro no que tange à participação feminina no mercado de trabalho, além de uma caracterização dos avanços referentes às questões de relações de gênero.

Esta pesquisa tem por objetivo elucidar o importante papel que as mulheres ocupam na sociedade moderna e, principalmente, nas organizações, além de esclarecer o significado do termo gênero, que é considerado mutável e extremamente ambíguo.

\section{Metodologia}

A presente pesquisa, de natureza teórica, foi realizada por meio de uma pesquisa bibliográfica em diversas publicações acerca do tema gênero e seus variantes, tais como: relações de gênero nas organizações, movimentos feministas etc. Realizou-se um levantamento bibliográfico e leitura de todos os artigos publicados sobre gênero nos anais do Encontro Nacional dos Programas de Pós-Graduação em Administração (ENANPAD) nos anos de 1998 a 2004, além de outros artigos publicados nos principais periódicos nacionais e internacionais sobre o tema gênero, escolhidos de forma aleatória (vide bibliografia).

\section{Revisão da literatura}

No ano de 2005, comemoraram-se os 30 anos do movimento feminista no Brasil. Portanto, são 30 anos de luta por salário igual para trabalho igual, livre acesso à contracepção, descriminalização do aborto, igualdade entre homens e mulheres na repartição das tarefas domésticas, o fim da violência doméstica, dentre outros.

Dentre os movimentos políticos e sociais do século $X X$, verifica-se que o feminismo foi um dos mais bem-sucedidos, assim como Sorj (2005, p. 03) coloca: 


\begin{abstract}
Diferentemente dos demais movimentos políticos como o fascismo, o nacionalismo e o comunismo, o feminismo promoveu uma formidável mudança de comportamentos orientada para a promoção de mais liberdade e igualdade entre os sexos, sem aspirar à tomada do poder, sem utilizar a força e sem derramar uma gota de sangue. As mudanças ocorreram no campo do convencimento e da persuasão, pela condução de campanhas e manifestações, pela divulgação de idéias na mídia e pela mudança das leis. O feminismo, além do mais, constitui-se como movimento plural, sem dono nem estruturas de controle centralizadas, sem excomungados, renegados ou dissidentes.
\end{abstract}

Craig (1992) e Kimmel (1992), entre outros, consideram que os estudos feministas produziram um corpo consistente de investigações empíricas e um nível de reflexão teórica fundamental para se entender como se dão as relações sociais baseadas na diferenciação sexual e, principalmente, que forneceram as ferramentas básicas para se processar mudanças nessas relações.

Os movimentos de mulheres se diferenciam em relação a outros movimentos ao proporem uma nova articulação entre a política e a vida cotidiana, entre esfera privada, esfera social e esfera pública. Ou seja, a mulher ao emergir da esfera privada para reivindicar na esfera pública também se torna visível na esfera social, onde os limites entre o público e o privado tornam-se confusos. Em um primeiro momento, as pesquisadoras feministas preocuparam-se em estudar essas mulheres, que se tornaram visíveis na sociedade e na academia, desvendando a mulher como um ser atuante e pensante.

A opressão das mulheres deve ser vista em termos de uma estrutura global de injustiça e opressão. Judy Chicago, em entrevista a Lester Strong, em 2002, disse que a opressão de gênero é a base sobre a qual outras formas de opressão são construídas, que é uma desigualdade básica e espelhada em todas as outras formas de desigualdade. Para ela, o feminismo é uma transformação revolucionária do planeta (STRONG, 2002).

A sociedade patriarcal é construída sobre o desempoderamento ${ }^{4}$ da mulher. Mas por que a sociedade patriarcal quer manter o poder com os homens? O poder não é racional. É como Tadeusz Borowski, um sobrevivente dos campos de concentração nazista, citado em Strong (2002), disse: "O mundo não é construído pela razão ou justiça. O mundo é construído pelo poder. E o poder não é racional. O desejo por poder não é racional". O problema, em âmbito global, é que as sociedades patriarcais são destrutivas não apenas para as mulheres, mas para o planeta. Judy Chicago, em entrevista a Lester Strong em 2002, fala da necessidade de revisão dos valores da sociedade como forma de impedir as conseqüências negativas do patriarcado sobre o mundo em que vivemos:

Eu acho que nós estamos em um tipo de corrida contra o tempo. O que acontecerá? O patriarcado se transformará? Ou o mundo chegará ao fim? Eu quero dizer, nós não podemos continuar desse jeito. Não estamos mais falando apenas sobre assuntos de gênero. Assim como Bell Hooks diz em Feminism is for Everybody (HOOKS, 2000), há mulheres com valores patriarcais e homens com valores feministas. Então, o que estamos falando é sobre a necessidade de uma revolução de valores. [...] Feminismo é sobre justiça social: justiça social

\footnotetext{
${ }^{4}$ Nota dos autores: o termo original em inglês, usado por Judy Chicago, em entrevista a Lester Strong, em 2002, é disempowerment.
} 
para todo o fim do sexismo, o fim da opressão patriarcal. O feminismo é um movimento radical de justiça social, com objetivos globais (STRONG, 2002, p. 08).

Dessa forma, percebe-se que, nas últimas décadas, houve um desenvolvimento da pesquisa sobre gênero, tema antes considerado simples e sem ambigüidades e hoje enxergado como altamente complexo, dinâmico e ambíguo (CALAS e SMIRCICH, 1992; HARDING, 1987). Esse desenvolvimento é, em parte, associado ao surgimento do pós-modernismo/ pós-estruturalismo (NICHOLSON, 1990). Conceitos como homens e mulheres, masculino e feminino são vistos cada vez mais como ambíguos e mutáveis. Gênero é visto, por muitos pesquisadores e pesquisadoras, como uma construção social e lingüística, como um significado instável atribuído ao masculino e ao feminino. A introdução da questão de gênero objetivou substituir a concepção naturalizada de sexo e enfatizou a questão dos papéis que homens e mulheres exercem na sociedade, que são papéis sociais.

O termo "gênero", como define Scott (1990), é empregado para designar as relações sociais entre os sexos significando, assim, uma maneira de indicar 'construções sociais' - a criação inteiramente social de idéias sobre os papéis adequados aos homens e às mulheres. É uma maneira de se referir às origens exclusivamente sociais das identidades subjetivas dos homens e das mulheres. O gênero é, segundo essa definição, uma categoria social imposta sobre o corpo sexuado.

Para Louro (2000), gênero se caracteriza como uma construção social feita sobre as diferenças sociais. Trata-se, portanto, do modo como essas diferenças sexuais são compreendidas numa dada sociedade, num grupo, em um contexto determinado por um processo histórico.

Para Laurentis (1994), o termo gênero não pode ser entendido como sexo, como a condição natural das pessoas, e sim a representação de cada indivíduo em termos de uma relação social preexistente ao próprio indivíduo e predicada sobre a oposição 'conceitual' e rígida (estrutural) dos dois sexos biológicos.

Albuquerque Jr. (2000) reconhece a pouca ênfase que a historiografia de gênero dedica ao masculino e às "experiências-de-ser-homem", considerando ser esta uma importante área para os estudos das relações sociais entre os sexos, desde que abordados pela perspectiva relacional que a metodologia de gênero possibilita. Ele diz que as práticas cotidianas de gênero, de ser homem, não estão determinadas nem pelos códigos de sexualidade. O gênero nem é natural, sendo uma criação histórica e cultural, nem está preso completamente a uma ordem dominante de prescrições.

Tudo isso remete a questões como: O que é definido como sendo masculino ou feminino em diversas situações? Como os discursos e as relações de gênero influenciam as organizações e como as organizações constroem o gênero? Talvez o aspecto mais importante seja que respostas definidas e finais não são possíveis. Teorias locais, historicamente conscientes, são enfatizadas em detrimento de teorias universais. A diversidade é enfatizada. Classe social, raça, orientação sexual, idade, situação familiar, condições nacionais e regionais, estilo de vida, e interesses pessoais podem ser vistos como fontes vitais de diferenciação (CHAFETZ, 1989).

\subsection{Relações de gênero no Brasil}

Ao procurar entender gênero como categoria de análise organizacional é necessário considerar a realidade brasileira, onde as relações se estabelecem a partir da trajetória histórica, social, cultural e econômica na quais as relações de gênero foram se construindo. Dessa forma, passar-se-á, agora, a conhecer como se efetivaram e se efetivam os estudos no Brasil. 
Em 1975, a ONU declara o início da Década da Mulher e, no Brasil, surgem os primeiros grupos feministas comprometidos em lutar pela igualdade das mulheres, pela anistia e pela abertura democrática. O crescimento expressivo da participação feminina no mercado de trabalho brasileiro a partir dos anos setenta é apontado por Bruschini (1994, p. 173) como "uma das mais marcantes transformações sociais ocorridas no país". A militância feminista chega aos sindicatos, mas sob a forma de departamentos femininos, apontados por Pinto (1994) como uma das formas de inserção e de construção de espaços de poder.

As mulheres, participando de movimentos populares, tanto urbanos quanto rurais, com reivindicações acerca do atendimento das necessidades básicas, começaram a perceber as relações de desigualdades a que estão submetidas e tornaram-se visíveis publicamente. Algumas se assumiram feministas, outras não.

Para Soares (1994), o movimento de mulheres nos anos setenta trouxe uma nova versão da mulher brasileira, que vai às ruas na defesa de seus direitos e necessidades e que realiza enormes manifestações de denúncia de suas desigualdades.

Nos anos oitenta, grupos feministas espalhavam-se pelos principais centros urbanos do país.Reorganizando a sociedade, rearticulando relações de poder, podendo ou não se transformar em lobby frente ao Estado, como ocorreu na Assembléia Constituinte de 1988. ${ }^{5}$

A partir dos anos noventa, houve uma dispersão e flagrante institucionalização dos movimentos feministas. Algumas dessas mudanças podem ser identificadas no rápido crescimento das ONGs (Organizações Não-Governamentais) feministas, nas participações em fóruns nacionais e internacionais de discussão e nas presenças significativas nos aparelhos de Estado. A especialização temática e a formação de redes também demonstram novas práticas sociais. Os temas se especificaram, tais como saúde, direitos, meio ambiente, violência, entre outros. Alguns movimentos perderam o caráter espontâneo e não-hierárquico e disseminaramse pelo país, financiados por organismos nacionais ou internacionais.

No debate acadêmico, as questões da igualdade ou da diferença assumem a forma de muitos trabalhos teóricos e pesquisas empíricas nas Ciências Sociais, especialmente na Sociologia, Antropologia e História. O debate feminista, hoje, parece estar restrito às academias com feministas profissionais e as práticas limitam-se às ONGs, com reivindicações específicas que se desenvolvem onde o Estado é omisso, como as questões ambientais.

Mas não se pode deixar de mencionar que, embora a mulher esteja participando ativamente no mercado de trabalho, as relações sociais ainda são marcadas por relações de gênero. A diferença salarial entre homens e mulheres que exercem a mesma função ainda é evidente.

Com o processo de reestruturação produtiva, essas questões de gênero emergem em maior intensidade, visto que as organizações têm procurado por diversidade para a formação de seus quadros de pessoal, para promover a criatividade e flexibilidade em seus produtos e processos. Assim, aliadas ao aumento do número de mulheres entrando no mercado de trabalho, as organizações, em geral, também se têm mostrado mais "receptivas" ao trabalho feminino. De acordo com o Instituto Brasileiro de Geografia e Estatística (IBGE), citado por Uchinaka (2004), as mulheres representam quase metade da População Economicamente Ativa (PEA) do país e, desse total, 38\% encontram-se empregadas.

\footnotetext{
${ }^{5}$ Conhecido como lobby do batom, a bancada feminina conseguiu, junto com as Emendas Populares, grandes conquistas que foram asseguradas pela Constituição (PINTO, 1994). Segundo Borba (1994), o lobby do batom disseminou-se em todo o país com intensas mobilizações de mulheres.
} 
Além disso, com relação à discriminação salarial, dados da Pesquisa Mensal de Emprego e Desemprego, divulgada pelo IBGE em junho de 2004, revelam que as mulheres brancas ganham, em média, 20,5\% menos do que os homens brancos, enquanto as negras recebem $19,4 \%$ menos do que os homens negros e $61,2 \%$ menos do que os homens brancos (UCHINAKA, 2004).

Entretanto, para Cappelle et al. (2004), essa receptividade ao gênero feminino deve ser analisada com cautela, pois, apesar da maior abertura para a entrada de mulheres nas organizações, não são todos os postos que se mostram disponíveis para serem ocupados por elas. Essas autoras identificaram que, na verdade, a entrada do contingente feminino no ambiente organizacional tem sido sujeita a algumas limitações quanto ao acesso a cargos que exigem maior qualificação ou que apresentam maiores possibilidades de ascensão na carreira. Madruga et al. (2001) argumentam que, no campo da liderança, o modelo predominante ainda é masculino.

\subsection{As mulheres e o mercado de trabalho}

De acordo com Kroska (1997), a mulher realiza o trabalho da casa porque essas atividades lhe permitem confirmar os significados culturais ligados à sua identidade feminina, ao passo que o homem enfoca o trabalho pago e evita o doméstico porque esse padrão de conduta afirma a sua identidade masculina. Isso indica que o marido (um ator poderoso) sustentará a sua imagem de potência se a sua esposa (um ator menos poderoso) servi-lo por meio do trabalho doméstico. Isso também indica que a esposa sustentará sua imagem de relativa impotência se o seu marido a protege e sustenta financeiramente. Dessa forma, o marido pode manter a sua imagem de relativa força quando a sua esposa o serve domesticamente, e uma esposa pode afirmar a sua impressão de maior delicadeza se o seu marido a sustenta.

No entanto, em um processo que se iniciou nos anos 1930 e intensificou-se a partir da década de 1970, as mulheres da classe média e da classe trabalhadora começaram a pensar menos nos deveres do lar e mais em seus trabalhos e em suas carreiras do que as gerações anteriores, iniciando um questionamento que se estendia da vida profissional para a vida pessoal (MADRUGA et al., 2001; SHARPE, 2001; THAYER, 2001; TONELLI, 2001; VILAS BOAS, PAULA NETTO e BARROS, 2001).

Segundo Oliveira, Oliveira e Dalfior (2000), a inserção cada vez maior das mulheres no mercado de trabalho, aliada aos movimentos feministas da pós-modernidade, que buscavam, basicamente, a igualdade de direitos e de tratamento perante os homens, trouxe um novo dinamismo às organizações burocráticas. Nesses termos, as mulheres tornaram-se mais propensas a assumir cargos de maior responsabilidade e de maior exigência técnica, apesar de ainda persistirem as diferenças salariais, a discriminação quanto ao estado civil e quanto à aparência física.

Associados a esse movimento, a reestruturação produtiva e o desenvolvimento tecnológico trouxeram um novo eixo de priorização para as organizações. Na busca por maior flexibilidade e necessitando acompanhar as mudanças ambientais ocorridas em nível mundial, as organizações vêm passando por uma completa reorganização de seus processos produtivos.

A tendência geral - tanto no setor público quanto no privado - tem sido uma mudança de estruturas altamente burocráticas para formas organizacionais "orgânicas". Segundo Edwards et al. (1999), essa mudança tem, geralmente, envolvida uma descentralização significante com uma mudança de autoridade para unidades estratégicas de negócio. Essa reordenação 
apresenta um desafio ao poder do grupo dominante masculino e a oportunidade de remediar a desigualdade de gênero.

As questões de gênero passam, então, a fazer parte de uma contextualização mais ampla na teoria das organizações. De visão tradicional de burocracia, em que se disseminam valores de impessoalidade, as organizações passam a incorporar novos atributos. Destarte, aceitar características, como emoção, intuição, sensibilidade, flexibilidade, capacidade de persuasão e afetividade, pode dar um novo direcionamento à tradicional forma de conceber uma organização burocrática (OLIVEIRA, OLIVEIRA e DALFIOR, 2000).

Nesse cenário contemporâneo, alguns teóricos defendem que o mercado de trabalho está mais aberto à inserção das mulheres, colocando em discussão a divisão tradicional entre masculino e feminino. Para Lavinas (1997), está acontecendo, como conseqüência da reestruturação produtiva, uma inversão de valores decorrentes da perda de postos de trabalho pelos homens. Para a autora, pode ser observado um aumento das ofertas de trabalho em atividades típicas do setor terciário, preenchidas, principalmente, pelas mulheres e, portanto, as mais beneficiadas com a reestruturação. Além disso, os homens não estariam dispostos a concorrer a tais empregos com as mulheres.

Outro aspecto salientado por alguns autores se refere ao estilo feminino em desempenhar suas funções. Machado (1999) sugere que o estilo das mulheres é marcado pelo senso de responsabilidade que as leva a uma melhor realização de suas atividades, implicando em uma maior satisfação dos envolvidos no processo de trabalho.

A busca da qualidade, segundo essa autora, é uma tendência no comportamento das mulheres empreendedoras. O desejo de realização, o estilo de liderança - voltado para as pessoas e não para as tarefas - e o estilo de decisão são características que, conjuntamente, fazem com que as empresas gerenciadas por mulheres tenham alta taxa de sobrevivência no mercado.

Abreu (1993) afirma que, ao longo dos anos 80, houve uma entrada maciça de mulheres bem educadas e qualificadas no mercado de trabalho. Esse fator se torna visível quando se destaca o nível educacional como uma das características de importância fundamental, funcionando mesmo como variável de seleção.

Em sua primeira pesquisa sobre a presença da mulher em postos de comando do mercado de trabalho brasileiro, realizada em 2005, o IBGE constatou que 3,9\% das 35,35 milhões de mulheres ocupadas no país na época da pesquisa ocupavam uma posição de "dirigente" nos locais de trabalho. Entre os homens, a proporção era de 5,5\% dos 49,24 milhões de ocupados.

A Síntese dos Indicadores Sociais, espécie de sintonia fina dos dados da Pesquisa Nacional por Amostra de Domicílios (PNAD), divulgada no segundo semestre de 2005, efetivamente confirma essa desvantagem feminina. A mulher tem mais tempo de estudo $(8,6$ anos contra 7,6 anos entre a população ocupada), mas esse esforço ainda não se traduz em recompensa no mercado. Entre as pessoas com 12 ou mais anos de escola, o rendimento médio auferido pela mulher representa apenas $61,6 \%$ do salário médio masculino (IBGE apud VALOR, 2006).

Ainda de acordo com dados do IBGE, na região nordeste, o número cai para 57,7\%, subindo para um pico de $62,9 \%$ do salário masculino na região Sul. Nas faixas de escolaridade menor, a diferença tende a cair, chegando a $80,8 \%$ entre pessoas com até quatro anos de estudo. A menor desigualdade de rendimento por sexo entre as pessoas com menor escolaridade se confirma na observação dos números entre $40 \%$ mais pobres e os $10 \%$ mais ricos da população brasileira. Entre os mais pobres, a renda média da mulher representa $76 \%$ da do homem. Entre 
os $10 \%$ mais ricos, a relação cai para $66,1 \%$, e, na região Sul, a mulher do grupo dos mais ricos recebe apenas 59,4\% do que ganha o homem (IBGE apud VALOR, 2006).

Enquanto entre os homens com nível de educação superior foi observada tendência à distribuição diversificada no mercado de trabalho, com 17,1\% empregados nas áreas de educação, saúde e serviços sociais, $16,3 \%$ na indústria, 15\% no comércio e reparação e 13,1\% na administração pública, entre as mulheres havia concentração de 46,1\% dos empregos em educação, saúde e serviços sociais (IBGE apud VALOR, 2006).

Além de ganhar menos pelo mesmo trabalho, a mulher continua trabalhando mais quando volta para casa. A mulher que trabalha fora dedica 22,1 horas semanais aos afazeres domésticos, caracterizando a clássica dupla jornada, enquanto entre os homens esse tempo é menos da metade, 9,9 horas.

No Piauí e no Maranhão, as mulheres chegam a dedicar em média 27,8 horas extras ao trabalho dentro de casa. No Distrito Federal, o extremo oposto, a mulher faz 17,3 horas extras semanais trabalhando em casa, contra 8,7 horas do homem (IBGE apud VALOR, 2006).

A inserção cada vez maior das mulheres no mercado de trabalho é confirmada também por Robbins (2000). Segundo ele, nas últimas três décadas, dobrou o número de mulheres no mercado de trabalho no Brasil e, atualmente, mais da metade das mulheres brasileiras trabalham.

No caso das mulheres casadas, no ano de 1989, 39\% faziam parte da força de trabalho, tendo este percentual se elevado para $48,5 \%$ no ano de 2000 . Além disso, no final da década de 90 , verificou-se que, em torno de $82 \%$ de todas as mulheres brasileiras com idade para trabalhar estavam empregadas.

Nos anos 90, de acordo com Mussak (2000), enquanto a renda média das mulheres brasileiras aumentou 43\%, a dos homens aumentou 19\%. A taxa de emprego no ano de 2000 aumentou $0,6 \%$ para os homens e 1,5\% para as mulheres. Seis capitais brasileiras, incluindo a maior cidade da América Latina, eram governadas por mulheres no ano de 2001, fazendo com que o número total de prefeitas passasse de 171 para 317, de 1992 a 2001.

O número de eleitoras brasileiras é maior que o de eleitores. Além disso, no exercício da advocacia, 59\% são mulheres; da medicina, 54\% e as juízas já ocupam 29\% das vagas. De acordo com Neves (2000), destacando os dados do IBGE, publicados na Revista Veja, em 2000, existiam $97 \%$ de assistentes sociais, $89 \%$ de psicólogas e $77 \%$ de professoras, dentre as pessoas que declararam imposto de renda no Brasil.

Este ambiente marcado por profundas transformações demográficas, socioeconômicas e culturais, nos últimos anos, repercutiu intensamente nas diferentes esferas da vida familiar. Verificou-se a redução do tamanho das famílias e o crescimento da proporção destas, cujas pessoas responsáveis são mulheres. O Censo Demográfico de 2000 revelou que 24,9\% dos domicílios tinham mulheres como responsáveis.

Mais confiantes e mais independentes, as mulheres já não se perguntam a respeito das possibilidades de inserção no mercado: as novas inquietações dirigem-se ao ambiente de trabalho no qual elas agora se encontram inseridas (ROULEAU, 2001; SHARPE, 2001). Se as mulheres deram importantes e decisivos passos em direção à busca da igualdade no trabalho, os homens parecem não ter acompanhado esse avanço.

No que tange à remuneração, por exemplo, as mulheres têm enfrentado alguns obstáculos. Em 2003, no Brasil, a média salarial das mulheres representava 69,6\% da média dos homens. Além disso, no ano de 1998, 10,5\% das mulheres ocupadas não recebiam remuneração e metade delas recebia menos de um salário mínimo, enquanto, em relação aos homens ocupados, essas proporções eram de 6,4\% e 30\%, respectivamente. Em 1999, 17\% da 
população ocupada masculina recebiam até um salário mínimo, contra 24,7\% da população feminina. Entre os assalariados que recebiam na faixa de 20 salários mínimos de rendimento por trabalho, verificou-se que $2,9 \%$ eram do contingente masculino e apenas $1,1 \%$ do feminino (IBGE, 2002).

Inúmeras mulheres fazem questão de posicionarem-se como pessoas que rejeitam a idéia milenar de que as obrigações femininas estão todas atreladas à rotina do lar e ao atendimento das necessidades do núcleo familiar; na prática, entretanto, as restrições impostas pelas exigências das tarefas domésticas parecem continuar sendo vistas - pelas próprias mulheres - como naturais, inevitáveis e mais prementes do que uma carreira profissional que exija independência em relação à família (BOSCARIN, GRZYBOVSKI e MIGOTT, 2001; CHARLES et al., 2001; SILVA, VILAS BOAS e BRITO, 2001; STAPLETON, 2001; VAN EERDEWIJK, 2001).

No Brasil, pesquisas detectaram algumas queixas, insatisfações, inseguranças e angústias da mulher na vida profissional: a discriminação impedindo ascensão profissional e restrição aos cargos de responsabilidade nas empresas (BETIOL, 2000; SILVA, VILAS BOAS e BRITO, 2001); a percepção de que o fato de ser casada e ter filhos seria responsável pelo maior nível de exigência e cobrança por parte dos superiores hierárquicos (OLIVEIRA, OLIVEIRA e DALFIOR, 2000); a injustiça de, apesar de normalmente possuir melhor qualificação profissional, ocupar posições hierárquicas de nível inferior, sempre submissa ao estilo gerencial masculino (MADRUGA et al., 2001); a decepção diante da desvalorização, pelo marido e pela família, das dificuldades impostas pela dupla jornada de trabalho (PAULA NETTO, CAPELLE e VILAS BOAS, 2001); a sensação de impotência diante da percepção de que não apenas os superiores em comando, mas também os clientes da empresa podem assumir atitudes machistas geradoras de situações inaceitáveis de discriminação (VILAS BOAS, PAULA NETTO e BARROS, 2001); o imperativo de assumir o discurso e as atitudes impostas pelo modelo masculino para obter ascensão ou sucesso profissional (OLIVEIRA, OLIVEIRA e DALFIOR, 2000 ; SILVA, VILAS BOAS e BRITO, 2001).

Além disso, relatos de mulheres que se moveram para o centro e para o topo das estruturas organizacionais revelam que um grande jogo de ambivalência e complexidade acompanha a ocupação dessas posições. Muitas encontram pressões e dificuldades na tentativa de executar o poder que elas supostamente acumularam dentro das camadas estruturais. Apesar de elas ocuparem formalmente uma posição de responsabilidade, a maneira como o gênero é conceituada, assim como os relacionamentos e as redes (masculinas) preexistentes, podem significar que elas ainda não estão 'incluídas' por outros membros da elite poderosa, mas permanecem 'nas margens' (SIMEONE, 1978).

\section{Considerações finais}

A realização deste estudo permitiu concluir, no campo teórico, que, realmente, a sociedade ocidental e as organizações que dela fazem parte estão sofrendo as influências da participação cada vez maior da mulher, tanto no contexto social como organizacional. A partir disso, estão se dispondo a enfrentar as conseqüências deste novo contexto e ampliar o enfoque diretivo e a tomada de decisão para a inserção dos valores femininos, respeitando a percepção das mulheres tanto nas questões sociais como nas organizacionais.

De acordo com Capra (1988), o poder do patriarcado tem sido difícil de entender por ser extremamente preponderante, tem influenciado as idéias mais básicas acerca da natureza humana e de sua relação com o universo. Nas palavras de Capra (1988, p. 27), o patriarcado: 
Era o único sistema que, até data recente, nunca tinha sido abertamente desafiado em toda a história documentada, e cujas doutrinas eram tão universalmente aceitas que pareciam constituir leis da natureza; na verdade, eram usualmente apresentadas como tal. Hoje, porém, a desintegração do patriarcado tornou-se evidente. O movimento feminista é uma das mais fortes correntes culturais do nosso tempo, e terá um profundo efeito sobre a nossa futura evolução.

As sociedades são organizadas em torno de uma 'norma' masculina, e é através de reflexão e ação que mulheres e homens podem questionar essa norma e formular propostas a harmonizar as relações sociais e individuais. Esse processo de reflexão e ação é participativo e de delegação. Mulheres e homens são atores-chave na mudança social. Embora as relações de gênero sejam, em sua maioria, desiguais, a mudança em direção à igualdade é possível.

A desigualdade de gênero origina-se na ideologia patriarcal, a qual suporta a maioria das convenções sociais sobre as quais as sociedades de hoje estão baseadas. Walters (2002) argumenta que uma mudança em direção a uma maior igualdade de gênero requer uma mudança no âmbito das instituições que governam nossa vida diária, estruturam nossas relações sociais e criam e mantêm sociedades nas quais relações desiguais (de poder) são expressas em relações de gênero existentes, assim como por meio de classe, casta, religião e etnia.

Algumas teorias feministas apontam que gênero não é mais divisor do que outras características, tais como: pobreza, classe, etnia, raça, identidade sexual, habilidade física e idade (HOOKS, 1984; JORDAN, 1981; LORDE, 1984). Em outras palavras, há multiplicidade e diversidade dentro de locais variados: situações e experiências de homens e mulheres dentro das organizações podem ser altamente variáveis, não passíveis de serem reduzidas às amplas generalizações da dicotomia mulher/homem.

Para Alvesson (1998), os estudos de gênero deveriam considerar mais abertamente a convergência, a divergência, as interações complexas entre várias masculinidades e feminilidades, a promoção de oportunidades de homens e mulheres e o bem-estar. Idéias sobre masculinidades e feminilidades nos estudos de gênero precisam ser radicalmente repensadas uma vez que as mudanças sociais transcendem sua relevância empírica e seu uso teórico.

Os números demonstram que, pela sua competência, a mulher está ocupando um novo lugar na sociedade. O crescente volume de publicações relacionadas a essa temática denota claramente o movimento social de valorização da mulher e apontam para um processo irreversível de modernização do ambiente organizacional e econômico (MADRUGA et al., 2001).

A identidade feminina, como algo que se constrói enquanto modus operandi, articulase ao social em múltiplos aspectos. É uma construção à qual se confere o poder de promover mudanças não apenas pessoais, mas na sociedade como um todo e, portanto, tem caráter militante, embora denegado; reflete a crise da modernidade, promovendo um questionamento do mundo patriarcal (BAHIA e FERRAZ, 1999).

É preciso reconhecer que as organizações são inerentemente "masculinas", isto é, foram criadas em sua grande maioria por homens e para homens; sistemas organizacionais, práticas de trabalho, estruturas e normas tendem a refletir a experiência masculina, valores masculinos e situações de vida masculinas. Como resultado, tudo o que é considerado normal e lugar-comum no trabalho tende a privilegiar traços que são social e culturalmente atribuídos aos homens, enquanto desvaloriza e ignora aqueles atribuídos às mulheres (ELY e MEYERSON, 1999). 
$\mathrm{Na}$ maioria das vezes, as organizações ignoram, dispensam ou desvalorizam sistematicamente o conhecimento e as perspectivas que as mulheres - e os demais grupos marginalizados - possuem e que geralmente são importantes e competitivamente relevantes, mas isso se desvia da "sabedoria" aceita que geralmente tem prevalecido.

Há uma tendência de mudança das máquinas burocráticas para formas e valores organizacionais que são potencialmente mais abertos para serem construídos de formas nãomasculinas e até femininas (GHERARDI, 1995). Isso não significa, no entanto, que as novas formas e princípios organizacionais são construídos de formas diretamente reconhecidas como femininas ou convenientes para as mulheres.

As possibilidades históricas que favoreceram a entrada da mulher no mercado de trabalho abriram espaço para o questionamento de um modelo de hegemonia patriarcal, e este questionamento, embora busque a afirmação de outra proposta modelar, não se encerra nisso, mas reflete, acima de tudo, a crise dos ideais de justiça e igualdade do processo civilizatório que ora se atravessa.

Em décadas recentes, as mulheres têm aumentado em grandes números a força de trabalho paga e muitas têm entrado em trabalhos anteriormente dominados por homens. As mulheres são alocadas para posições particulares vistas como mais femininas, e os trabalhos realizados por mulheres tornam-se definidos como "trabalho de mulher".

Não obstante à valorização do feminino, existem alguns entraves, como a menor remuneração em relação aos homens, a dupla jornada de trabalho e o maior índice de desemprego para mulheres que dificultam sua inserção no mundo do trabalho. Mesmo considerando esses entraves, não se pode negar que o quadro apresentado indica mudanças no comportamento da mão-de-obra, nas organizações e nas relações sociais que se desenvolvem em seu interior.

É possível considerar que as práticas de gênero estão inscritas no cotidiano organizacional e que, para quebrar a evidência desses processos, acontece um fato interessante, algumas mulheres bem-sucedidas ficam sob os holofotes.

Isso pode gerar algum conforto, mas não mais do que isso, enquanto tira a atenção das desigualdades sistemáticas de gênero. É importante que a existência de distinções seja reconhecida, ao invés de normas e valores correntes de igualdade, e que seja percebido que essas distinções são significativas para a prática organizacional, porque elas facilitam a (re) produção da desigualdade de gênero.

Os caminhos da mulher ainda são difíceis. A idéia de que a mulher precisa de proteção extra ou deve realizar as tarefas consideradas mais fáceis continua tão forte que, por exemplo, quando uma menina manifesta ousadia ou agressividade, ela é geralmente barrada para que se possa produzir mais tarde a mulher profissional ideal, aquela que aceita as tarefas secundárias e sufoca seu talento nos bastidores da história, onde tem permanecido invisível, como são em geral todos os oprimidos (WHITAKER, 1988).

Um exemplo de barreira social que dificulta o processo de igualdade tanto almejado pelas feministas, como foi mostrado por Carrara (2005), é a Igreja Católica que, assumindo paradoxalmente uma posição naturalista e condenando de fato toda a antropologia moderna, declara que a teoria de gênero, com seu correlato "construtivismo social", é uma ideologia perniciosa por não estabelecer uma relação necessária entre o sexo biológico e os papéis sexuais, ou seja, por não entender que sociedade e cultura, para serem abençoadas pela Igreja, devem girar em torno dos imperativos da natureza, ajudando-a a atingir os seus fins.

Constata-se que, apesar das suas diferenças, homens e mulheres não poderão mais se deter de procurar um entendimento entre as suas concepções de vida e de trabalho, para se comprometerem com o futuro das novas gerações das instituições que comandam o contexto 
das mudanças sociais e econômicas, dentre as quais se destacam as organizações (MADRUGA, 2001).

Fica evidenciada a importância do tema proposto e o quanto ainda se tem a percorrer para superar a histórica "batalha" entre os sexos. As disputas de espaço geradas pelo avanço da mulher no campo de dominação masculino apontam para a necessidade, cada vez mais urgente, de conscientização, tanto masculina quanto feminina, de que o futuro pertencerá àqueles que souberem harmonizar as características mais próprias de um ou de outro. As questões de gênero somente poderão caminhar para uma solução se o entendimento entre o masculino e o feminino for resultado de uma mudança conjunta, integrada e efetiva nas relações entre os sexos.

Uma vez que é limitada a nossa visão de um estado de igualdade de gênero considerando as relações sociais e a cultura tradicional, não é possível antecipar em qualquer detalhe com o que precisamente se parece um estado final e ideal. Ely e Meyerson (1999) sugerem que este processo de transformação - de resistência e aprendizagem - continue indefinidamente e ele mesmo constitua a meta de igualdade de gênero.

A libertação feminina é um processo histórico muito lento, ainda em andamento. Um assunto, portanto, que não oferece conclusão. Ao contrário, há muito ainda a se escrever sobre ele. A libertação feminina não ocorrerá totalmente nos marcos do tipo da sociedade atual, porque ela implica também a libertação masculina.

Contudo, não é somente com a questão de gênero que se deve preocupar, já que tanto homens como mulheres, tanto do Primeiro quanto do Terceiro Mundo, empregados ou desempregados, com ou sem famílias, lutam contra desigualdades, injustiças, iniqüidades e intolerância.

\section{Referências}

ABREU, A. R. P. Mudança tecnológica e gênero no Brasil: primeiras reflexões. Novos Estudos, São Paulo, n. 35, p. 121-132, mar. 1993.

ALBUQUERQUE JR., D. M. Nordeste: uma invenção do falo: uma história do gênero masculino no Brasil (1920-1970). Campinas: Unicamp (mimeo.). 2000.

ALVESSON, M. Gender relations and identity at work: a case study of masculinities and femininities in an advertising agency. Human

Relations, New York, v. 51, n. 8, p. 969-1005, Aug. 1998.
BAHIA, C.; FERRAZ, C. Entre a exceção e a regra: a construção do feminino na polícia civil baiana. In: ENCONTRO NACIONAL DOS PROGRAMAS DE PÓS-GRADUAÇÃO EM ADMINISTRAÇÃO, 1999. Anais... ANPAD, 1999. 1 CD-ROM.

BETIOL, M. I. S. Ser administradora é o feminino de ser administrador? In: ENCONTRO NACIONAL DOS PROGRAMAS DE PÓSGRADUAÇÃO EM ADMINISTRAÇÃO, 2000. Anais... Florianópolis: ANPAD, 2000. 1 CDROM. 
BORBA, A. O feminismo no Brasil hoje.Revista de Estudos Feministas, Rio de Janeiro, v. 2, n. 2, p. 117-149, 1994.

BOSCARIN, R., GRZYBOVSKI, D.; MIGOTT, A. M. B. Mulher, conhecimento e gestão empresarial: um estudo nas empresas familiares. In: ENCONTRO NACIONAL DOS PROGRAMAS DE PÓS-GRADUAÇÃO EM ADMINISTRAÇÃO, 2001. Anais... Campinas: ANPAD, 2001. 1 CDROM.

BOURDIEU, P. (1999). A dominação masculina. Rio de Janeiro: Bertrand Brasil.

BRUSCHINI, C. O trabalho da mulher no Brasil: tendências recentes. In: ENCONTRO NACIONAL DE ESTUDOS DO TRABALHO, 3. 1994, São Paulo. Anais... São Paulo: ABET v.1, p. 507-529, 1994.

CALAS, M. B.; SMIRCICH, L. Re-writing gender into organizational theorizing: directions from feminist perspectives. In: M. REED, M.; HUGHES, M. (Eds.). Re-thinking organization: new directions in organizational theory and analysis. London: Sage, 1992.

CAPPELLE M. C. A. et al. S. Relações de gênero, representações sociais e trabalho em uma organização militar. In: CRAMER, L.; BRITO, M. J.; CAPPELLE M. C. A Relações de gênero no espaço organizacional. Lavras: UFLA, 2004. p. $1-30$.

CAPRA, F. O Ponto de Mutação. Tradução: Álvaro Cabral. São Paulo: Cultrix, 1988. 447 p.

CARRARA, S. Sexualidade, religião e estado laico. 2005. Disponível em: < http://www.clam. org.br/publique/cgi/cgilua.exe/sys/start.htm > . Acesso em: 21 out. 2005.

CHAFETZ, J. S. Gender equality: toward a theory of change. In: WALLACE, R. (Ed.). Feminism and sociological theory. Newbury Park: Sage, p. 101-118, 1989.

CHARLES, M. et al. The context of women's market careers: a cross-national study, Work and Occupations, v. 28, n. 3, p. 371-396, Aug. 2001.
CRAIG, S. (Org.). Men, masculinity and the media: research on men and masculinities series. Newbury Park/London/New Delhi: Sage. 1992. v.1.

EDWARDS, C. et al. Lost opportunities? Organizational restructuring and women managers. Human Resource Management Journal, Londres, v. 9, n. 1, p. 55-64, 1999.

ELY, R. J.; MEYERSON, D. E. Moving from gender to diversity in organizational diagnosis and intervention. Diverity Factor, Filadélfia, v. 7, n. 3, p. 28-33, 1999.

FERGUSON, K. E. The feminist case against bureaucracy. Filadélfia: Temple University Press, 1984.

GHERARDI, S. Gender, symbolism and organizational cultures. London: Sage, 1995.

HARDING, S. Introduction: is there a feminist method? In: ___ (Ed.). Feminism and methodology. Bloomington: Indiana University Press, p. 181-190, 1987.

HOOKS, B. Feminism is for everybody. Cambridge, MA: South End Press, 2000.

HOOKS, B. Feminist theory: from margin to center. Boston: South End Press, 1984.

IBGE. Censo Demográfico 2000. Perfil das mulheres responsáveis pelo domicílio no Brasil. Instituto Brasileiro de Geografia e Estatística - IBGE. 2002. Disponível em: < http://www. ibge.gov.br/home/estatistica/populacao/ perfildamulher/perfilmulheres.pdf $>$ Acesso em: 21 out. 2005.

JORDAN, J. Declaration of an independence: I would just as soon not have in civil wars. Boston: Beacon Press, 1981.

KIMMEL, M. La producción teórica sobre la masculinidad: nuevos aportes. In: RODRIGUES, Regina (Ed.). Fin de siglo: genero y cambio civilizatorio. Santiago: Isis International, Ediciones de las mujeres, n. 17, p. 129-38, 1992.

KROSKA, A. The division of labor in the home: a review and reconceptualization. Social 
Psychology Quaterly, Washington, v. 60, n. 4, p. 304-322, dez. 1997.

LAURENTIS, T. "A tecnologia do gênero". In: HOLLANDA, H. B. de (Org.). Tendências e impasses: o feminismo como crítica da modernidade. Rio de Janeiro: Rocco, 1994. p. 206-242.

LAVINAS, L. Emprego feminino: o que há de novo e o que se repete. DADOS - Revista de Ciências Sociais, Rio de Janeiro, v. 40, n.1, p.4167, 1997.

LEONARD, P. Organizing Gender? Looking at Metaphors as Frames of Meaning in Gender/ Organizational Texts. Gender, Work and Organization, vol. 9, n. 1, jan. 2002.

LORDE, A. Sister outsider. Trunansburg, Nova York: The Crossing, 1984.

LOURO, G.L. Gênero e magistério: identidade, história e representação [on line]. 2000.

Disponível em: <www.ufrgs/faced/geerge/ duvida.html>. Acesso em: 05 jun. 2005.

MACHADO, H. V. Tendências do comportamento gerencial da mulher empreendedora. In: ENCONTRO NACIONAL DOS PROGRAMAS DE PÓS-GRADUAÇÃO EM ADMINISTRAÇÃO, 1999. Anais... Foz do Iguaçu: ANPAD, 1999. 1 CD-ROM.

MADRUGA, L. R., GOMES, C. M., FLEIG, D. G., ALTISSIMO, J. C. e COSTA, V. F. A Valorização da Mulher no Contexto do Trabalho: Contradições e Evidências Identificadas na Realidade Atual. In: ENCONTRO NACIONAL DOS PROGRAMAS DE PÓS-GRADUAÇÃO EM ADMINISTRAÇÃO, 2001. Anais... Campinas: ANPAD, 2001. 1 CDROM.

MUSSAK, E. Seja mulher. Revista T\&D desenvolvendo pessoas, São Paulo, a. VIII, n. 96, p. 12-13, 2000.

NEVES, C. Elas são a bola da vez. Revista T\&D desenvolvendo pessoas, São Paulo, a. VIII, n. 96, p. 36-43, 2000.

$\mathrm{NICHOLSON}$, L. J. (Ed.). Feminism/

postmodernism. Nova York: Routledge, 1990.
OLIVEIRA, N.; OLIVEIRA, R. C. M.; DALFIOR, S. R. Gênero e novas perspectivas de trabalho: um estudo junto a mulheres gerentes de atendimento no Banco do Brasil. In: ENCONTRO NACIONAL DOS PROGRAMAS DE PÓS-GRADUAÇÃO EM ADMINISTRAÇÃO, 2000. Anais... Florianópolis: ANPAD, 2000. 1 CD-ROM.

PAULA NETTO, A.; CAPELLE, M. C. A.; VILAS BOAS, L. H. B. "Na Rua da Amargura?" O significado da perda do emprego para as mulheres. In: ENCONTRO NACIONAL DOS PROGRAMAS DE PÓS-GRADUAÇÃO EM ADMINISTRAÇÃO, 2001. Anais... Campinas: ANPAD, 2001. 1 CD-ROM.

PINTO, C. Movimentos sociais: espaços privilegiados da mulher enquanto sujeito político. In: COSTA, A. O.; BRUSCHINI, C. (Orgs.). Uma questão de gênero. São Paulo: Rosa dos Tempos, p. 127-150, 1994.

ROBBINS, S. P. Administração: mudanças e perspectivas. São Paulo: Saraiva, 2000.

ROULEAU, L. Emoção e repertório de gênero nas organizações. In: DAVEL, E.; VERGARA, S. C. Gestão com pessoas e subjetividade. São Paulo: Atlas, 2001.

SCOTT, J. W. Gênero: uma categoria útil de análise histórica. Educação e Realidade, Porto Alegre, v.6, n. 2, jul./dez. 1990.

SHARPE, S. Going for it: young women face the future, Feminism \& Psychology, v. 11, n. 2, p. 125-142, 2001.

SILVA A. L.; VILA BOAS L. H. B.; BRITO M. J. As representações sociais sobre a mulher: percepções de gênero em uma agência bancária. In: ENCONTRO NACIONAL DOS PROGRAMAS DE PÓS-GRADUAÇÃO EM ADMINISTRAÇÃO. 25., 2001. Campinas. Anais... Campinas: ENANPAD, 2001. 1 CD-ROM

SIMEONE, A. Academic women: working towards equality. Massachusetts: Bergin and Garvey, 1978. 
SOARES, V. Movimento feminista: paradigmas e desafios. Revista de Estudos Feministas, Rio de Janeiro, n. especial, p. 203-2016, 2. sem. 1994.

SORJ, B. O estigma das feministas. 2005. Disponível em: < http://www.clam.org.br/ publique/cgi/cgilua.exe/sys/start.htm > . Acesso em: 21 out. 2007.

STAPLETON, K. Constructing a feminist identity: discourse and the community of practice,

Feminism \& Psychology, v. 11, n. 4, p. 459-491, 2001.

STROBER, M. Toward a general theory of occupational sex segregation: the case of public school teaching. In: RESKIN, B. F. (Ed.). Sex segregation in the workplace. Washington, DC: Brookings Institution, 1984. p. 144-156.

STRONG, L. Painting a revolution: a talk with Judy Chicago on art, gender, feminism, and power. International Journal of Sexuality and Gender Studies, v. 7, n. 4, p. 307-325, out. 2002.

THAYER, M. Transnational feminism: reading joan scott in the brazilian 'Sertão', Ethnography, v. 2, n. 2, p. 243-271, 2001.

TONELLI, M. J. A questão das relações amorosas e familiares. In: DAVEL, E.; VERGARA, S. C.

Gestão com pessoas e subjetividade. São Paulo: Atlas, p. 243-26, 2001.

UCHINAKA F. Mulher: mercado de trabalho é marcado por desigualdades. In: Combate ao racismo: Documentos, São Paulo, 2004. Disponível em <http://www. pt.org.br/site/secretarias_def/secretarias_int. asp? cod $=2665 \&$ cod_sis $=4 \&$ cat $=57>$ Acesso em: 20 mar. 2007.

VALOR. Mulheres ocupam 3,9\% dos cargos de chefia, revela IBGE. Disponível em: < http:// www2.uol.com.br/aprendiz/guiadeempregos/ executivos/noticias/ge170406.htm > . Acesso em: 11 ago. 2006.

VAN EERDEWIJK, A. How sexual and reproductive rights can divide and unite. The European Journal of Women's Studies, v. 8, n. 4, p. 421-439, 2001.
VILAS BOAS, L. H. B.; PAULA NETO, A.; BARROS, L. C. Representações da diferenciação e assimetrias de gênero no espaço organizacional: um estudo no setor de vendas de veículos. In: ENCONTRO NACIONAL DOS PROGRAMAS DE PÓS-GRADUAÇÃO EM ADMINISTRAÇÃO, 2001. Anais... Campinas: ANPAD, 2001. 1 CD-ROM.

WALTERS, H. Participatory gender auditing: a challenging process of learning and change. Geneve: ILO; G\&DTC, 2002.

WHITAKER, D. Mulher \& homem: o mito da desigualdade. São Paulo: Moderna, 1988. 98p. 